\title{
Polyvalent Immunoglobulin as a Potential Treatment Option for Patients with Recurrent COPD Exacerbations
}

This article was published in the following Dove Press journal: International Journal of Chronic Obstructive Pulmonary Disease

\author{
Dana Unninayar $\mathbb{D}^{\prime}$ \\ Sara J Abdallah ${ }^{2}$ \\ D William Cameron ${ }^{2-4}$ \\ Juthaporn Cowan $\mathbb{D}^{2-4}$ \\ 'Faculty of Medicine, University of \\ Ottawa, Ottawa, Ontario, Canada; \\ ${ }^{2}$ Clinical Epidemiology Program, The \\ Ottawa Hospital Research Institute, \\ Ottawa, Ontario, Canada; ${ }^{3}$ Division of \\ Infectious Diseases, Department of \\ Medicine, University of Ottawa, Ottawa, \\ Ontario, Canada; ${ }^{4}$ Centre of Infection, \\ Immunity and Inflammation, Department \\ of Biochemistry, Microbiology and \\ Immunology, University of Ottawa, \\ Ottawa, Ontario, Canada
}

\begin{abstract}
Chronic obstructive pulmonary disease (COPD) is characterized by chronic airway inflammation and episodes of worsening respiratory symptoms and pulmonary function, termed acute exacerbations of COPD (AECOPD). AECOPD episodes are associated with heightened airway inflammation and are often triggered by infection. A subset of COPD patients develops frequent exacerbations despite maximal existing standard medical therapy. It is therefore clear that a targeted and more effective prevention strategy is needed. Immunoglobulins are glycoprotein molecules that are secreted by B lymphocytes and plasma cells and play a critical role in the adaptive immune response against many pathogens. Altered serum immunoglobulin levels have been observed in patients with immunodeficiencies and inflammatory diseases. Serum immunoglobulin has also been identified as potential biomarkers of AECOPD frequency. Since plasma-derived polyvalent immunoglobulin treatment is effective in preventing recurrent infections in immunodeficient patients and in suppressing inflammation in many inflammatory diseases, it may be conceivable that immunoglobulin treatment may be effective in preventing recurrent AECOPD. In this article, we provide a review of the current knowledge on immunoglobulin treatment in patients with COPD and discuss plausible mechanisms as to how immunoglobulin treatment may work to reduce AECOPD frequency.
\end{abstract}

Keywords: chronic obstructive pulmonary disease, immunoglobulin treatment, exacerbation

\section{Introduction}

Chronic Obstructive Pulmonary Disease (COPD) is a burdensome illness associated with significant morbidity and mortality. Some individuals with COPD experience recurrent acute exacerbations (AECOPD), which are events characterized by a worsening of respiratory symptoms that are beyond normal day-to-day variation and lead to a change in medication and/or healthcare services. ${ }^{1}$ AECOPD accelerate disease progression and are the major cause of emergency department visits and hospitalizations. ${ }^{2,3}$ Current strategies to prevent and reduce AECOPD frequency include pharmacotherapy, patient vaccination and general self-management education. ${ }^{4}$ However, the efficacy of this approach is moderate at best and it is clear that a targeted and more effective prevention strategy is needed.

Plasma-derived immunoglobulin treatment has been used widely and effectively in patients who are susceptible to recurrent respiratory tract infections due to immunodeficiency. ${ }^{5,6}$ Although COPD is not considered a medical condition featured by immunodeficiency, recurrent respiratory tract infections are common in
Correspondence: Juthaporn Cowan The Ottawa Hospital, General Campus, 50 I Smyth Road, Box 223, Ottawa, Ontario, KIH 8L6, Canada

Tel +| 6/3-737-8899 X 796|7

$\mathrm{Fax}+1$ 613-737-8352

Email jcowan@toh.ca
International Journal of Chronic Obstructive Pulmonary Disease 2021:16 545-552 
this population. We and other have reported a positive effect of immunoglobulin treatment in COPD with respect to AECOPD frequency reduction. ${ }^{7,8}$ In this paper, we review the current evidence of immunoglobulin treatment in COPD patients and propose plausible mechanisms as to how Ig treatment may work to reduce AECOPD frequency.

\section{Immunoglobulin Treatment}

Immunoglobulin or antibody is a glycoprotein molecule produced by B-lymphocytes and plasma cells. It plays a critical role in the immune response against microbes and foreign substances. Effector functions of immunoglobulins are: 1) they bind to and inactivate microbes or toxins; 2) they activate the complement system to form a membrane attack complex - a cytotoxic pore on the surface of microbes; 3) they facilitate phagocytosis by opsonization. ${ }^{9}$ Hence, people who have low or abnormal immunoglobulins are predisposed to recurrent infections. Polyvalent immunoglobulins can be isolated from the purified plasma of thousands of healthy donors and therefore offer protection against a diverse spectrum of pathogens. ${ }^{10}$ The currently available immunoglobulin products are predominantly comprised of immunoglobulin G ( $\operatorname{IgG}$ ) isotype. ${ }^{11}$ Immunoglobulin treatment has been shown to reduce the number of serious and non-serious respiratory infections as well as the number of complications from recurrent infections (ie chronic lung diseases) in patients with primary and secondary immunodeficiencies. ${ }^{12}$ In addition to its anti-infective properties, immunoglobulin possesses anti-inflammatory and immunomodulatory properties which make immunoglobulin treatment an effective tool in the management of many systemic inflammatory and autoimmune conditions. ${ }^{13-16}$ Immunoglobulin treatment can be administered intravenously or subcutaneously and is generally well-tolerated.

\section{Current Evidence of Immunoglobulin Treatment in AECOPD Prevention}

We conducted a literature search to review the current evidence of the effectiveness of Ig treatment in preventing recurrent AECOPD in COPD patients. Our search revealed that only three studies have been conducted to investigate this treatment option and as such have been summarized below and in Table 1.

In a double-blind placebo-controlled study published in an abstract format, Barth et $\mathrm{al}^{17}$ evaluated the effects of
$16 \%$ immunoglobulin (dose $5 \mathrm{~mL}$; Beriglobin $\mathrm{S}$ ) vs serum albumin administered monthly for 12-months on AECOPD rates in 56 patients ( 28 per group). Compared to placebo, immunoglobulin did not have a significant effect on AECOPD frequency or airway resistance. However, patients randomized to immunoglobulin required a lower daily dosage of prednisone at the end of the study period although the result is not statistically significant. It is important to note that the immunoglobulin dosage in this study was determined by a volume-based strategy instead of the standard weight-based dosing strategy used in the treatment of immunodeficiency. A typical immunoglobulin treatment dosage is $0.4-0.8 \mathrm{~g} / \mathrm{kg} / \mathrm{month}$. Thus, for a $70 \mathrm{~kg}$ immunodeficient patient, approximately $35 \mathrm{~g}$ of immunoglobulin per month would be required. However, Barth et al only administered $0.8 \mathrm{~g}$ per month regardless of body weight. While it was found that AECOPD frequency and severity did not significantly differ in patients before and after receiving immunoglobulin treatment, there were several limitations including a small sample size, incomplete reporting (full article was not published), and a low immunoglobulin dosage. Further, two more recent studies have found statistically significant decreases in AECOPD frequency and severity after treatment with immunoglobulin.

In a retrospective longitudinal cohort study, our group examined the effect of immunoglobulin replacement therapy on recurrent AECOPD. ${ }^{7}$ Immunoglobulin administered at standard doses $(0.4-0.8 \mathrm{~g} / \mathrm{kg}$ body weight per month) significantly decreased the total number of AECOPD from $4.7 \pm 3.1$ episodes to $0.6 \pm 1.0$ episodes $(p=0.0001)$ in 14 cases. Strikingly, the number of AECOPD hospitalizations decreased significantly from 12 episodes to 1 episode per year following immunoglobulin treatment $(\mathrm{p}=0.016)$. This reduction in exacerbation and hospitalization frequency was consistent across all patients in the study regardless of COPD severity, presence of bronchiectasis, and baseline serum IgG levels. While these results are promising, the findings are limited by the retrospective nature, the absence of a control group, and a small sample size.

Finally, McCullagh et al reported a case series to describe the presence of concomitant antibody deficiency, diagnosed by pneumococcal vaccine response in 29 COPD patients with recurrent AECOPD. ${ }^{8}$ A subset of these patients $(9 / 29)$ were treated with Ig. Using a selfcomparative risk-interval analysis, they reported a significant reduction in the frequency of COPD 
Table I Summary of Study Characteristics and Study Outcomes

\begin{tabular}{|c|c|c|c|c|c|}
\hline Study & $\begin{array}{l}\text { Study } \\
\text { Design }\end{array}$ & $\begin{array}{l}\text { Number of } \\
\text { Patients }\end{array}$ & IG Dosage & $\begin{array}{l}\text { Observation } \\
\text { Period }\end{array}$ & Outcomes \\
\hline $\begin{array}{l}\text { Barth } 2001 \\
(\text { abstract only) }\end{array}$ & $\begin{array}{l}\text { Randomized } \\
\text { control trial }\end{array}$ & $\begin{array}{l}28-I G \\
28-\text { Albumin }\end{array}$ & $\begin{array}{l}5 \mathrm{~mL} \text { of } 16 \% \text { Intravenous } \\
\text { Immunoglobulin (IVlg) } \\
\text { monthly }\end{array}$ & I year & $\begin{array}{l}\text { No significant difference in } \\
\text { - Number and duration of } \\
\text { exacerbations } \\
\text { - Change of airway resistance } \\
\text { - Time to first exacerbation } \\
\text { - Duration of hospitalization due } \\
\text { to exacerbation } \\
\text { - Number of proven infections } \\
\text { But a trend in less prednisolone } \\
\text { use in the Ig group }(p=0.1)\end{array}$ \\
\hline Cowan $2015^{7}$ & $\begin{array}{l}\text { Retrospective } \\
\text { longitudinal } \\
\text { cohort }\end{array}$ & 14 & $\begin{array}{l}\text { Did not specify but } \\
\text { standard dosing as } \\
\text { a replacement therapy for } \\
\text { immunodeficiency - } \sim 30 \mathrm{~g} / \\
\text { month. }\end{array}$ & I year & $\begin{array}{l}\text { The incidence of AECOPD was } \\
\text { consistently and significantly } \\
\text { reduced in frequency from mean } \\
4.7( \pm 3.1) \text { per patient-year before, } \\
\text { to } 0.6( \pm I .0) \text { after immunoglobulin } \\
(I g) \text { treatment ( } p=0.000 \mathrm{I}) \text {. There } \\
\text { were twelve episodes of severe } \\
\text { AECOPD (in seven cases) in } \\
\text { the year prior, and one in the year } \\
\text { of Ig treatment }(p=0.016) \text {. }\end{array}$ \\
\hline McCullagh $2017^{8}$ & $\begin{array}{l}\text { Retrospective } \\
\text { case series }\end{array}$ & $\begin{array}{l}\text { Total }=29 \text { (9 lg } \\
\text { treatment, } 13 \\
\text { prophylactic } \\
\text { antibiotics, } 7 \text { no } \\
\text { treatment) }\end{array}$ & $\begin{array}{l}\text { 300-600 mg/kg/4-week } \\
\text { period every 3-4 weeks } \\
\text { for IVlg or every I-2 } \\
\text { weeks for SClg. } \\
\text { Antibiotic regimens: } \\
\text { trimethoprim/ } \\
\text { sulfamethoxazole I } \\
\text { double strength tablet } \\
\text { twice daily alternating } \\
\text { with doxycycline } 100 \mathrm{mg} \\
\text { twice daily every two } \\
\text { weeks, or azithromycin } \\
250-500 \text { mg three times/ } \\
\text { week }\end{array}$ & $\begin{array}{l}\text { At least one and } \\
\text { up to } 10 \text { years } \\
\text { before and after } \\
\text { diagnosis and } \\
\text { treatment } \\
\text { initiation }\end{array}$ & $\begin{array}{l}\text { In those receiving } \mid g \text {, there was } \\
\text { a reduction in annual courses of } \\
\text { steroid from } 12(4.5-\mid 2) \text { to } 0.5 \\
(0-I .5)(p=0.03 \mid) \text { and annual } \\
\text { courses of rescue antibiotic from } 9 \\
(5.5-\mid 2) \text { to } 0(0-\mid .5)(p=0.0 \mid 6) \text {. } \\
\text { Annual acute exacerbations in this } \\
\text { group decreased from } 4(3-5.5) \text { to } \\
0.5(0-\mid .5)(p=0.0 \mid 6) \text {. Numbers } \\
\text { were too small to see a difference } \\
\text { in annual rates of hospital } \\
\text { admission for } A E C O P D \text { pre- } \\
\text { treatment } I .5(I-3) \text { and post- } \\
\text { treatment } 0(0-I .5)(p=0.25) \text {. }\end{array}$ \\
\hline
\end{tabular}

exacerbations, hospitalizations due to AECOPD, corticosteroid use, and rescue antibiotics administration in those who received Ig. Their report of an apparent steroidsparing effect due to Ig treatment is consistent with earlier findings from Barth et al. ${ }^{17}$

Based on the studies described above, there is a limited evidence on the use of immunoglobulin treatment in COPD. However, the existing data invites further research on this topic. While determining the therapeutic effect of immunoglobulin treatment in a well-designed prospective study is essential, it is also important to explore the potential mechanisms of immunoglobulin treatment in COPD in order to better target COPD patients who will benefit from the treatment.

\section{Proposed Mechanisms of Immunoglobulin Treatment in AECOPD Prevention}

Below is a summary of several mechanisms by which immunoglobulin treatment could act to reduce exacerbation frequency and severity. 


\section{Replacement Therapy for Hypogammaglobulinemia}

Low serum immunoglobulin G (IgG) level, or hypogammaglobulinemia, has been shown to be associated with frequency of AECOPD in a large cohort of 653 patients with COPD. ${ }^{18}$ An additional study of 262 stable COPD patients followed prospectively for five years in Norway also showed that hypogammaglobulinemia was associated with higher risk for AECOPD. ${ }^{19}$ The cause of hypogammaglobulinemia in these cases is not well known. However, it should be recognized that corticosteroids have been the mainstay treatment for AECOPD, and hence frequent or prolonged use of corticosteroids is inevitable in individuals at high-risk of exacerbations. ${ }^{20}$ It is well-known that administration of corticosteroids such as prednisone can suppress the immune system and is associated with reduced serum IgG levels. ${ }^{21,22}$ This poses a causality dilemma of whether frequent use of corticosteroids in COPD patients induces hypogammaglobulinemia or whether hypogammaglobulinemia predisposes patients to recurrent AECOPD and hence prolonged corticosteroid use. Regardless of causal direction, correction of hypogammaglobulinemia with immunoglobulin treatment may interrupt the AECOPD-hypogammaglobulinemia process. It should be noted however that we observed a reduction in AECOPD rates in COPD patients at highrisk of exacerbations despite having normal baseline serum IgG level. ${ }^{7}$ Therefore, immunoglobulin treatment is unlikely to be working solely by replacement of the diminished level of serum IgG.

\section{Treatment of Humoral Immunodeficiency}

Humoral immunodeficiency or antibody deficiency is a result of any abnormality in the humoral immune system that contributes to an ineffective immune response and recurrent infections. Hypogammaglobulinemia is only a subset of humoral immunodeficiency and hence patients may have normal or elevated IgG levels but may still have humoral immunodeficiency due to other mechanisms. Humoral immunodeficiency may be broadly categorized as primary humoral immunodeficiency, which is inherited, and secondary humoral immunodeficiency, which is acquired. Examples of primary humoral immunodeficiency include common variable immunodeficiency disease and X-linked agammaglobulinemia. Secondary humoral immunodeficiency conditions are most commonly caused by hematological malignancies (eg, chronic lymphocytic leukemia) and immune-modulating medications (eg, rituximab, which depletes B cells). ${ }^{23}$
Patients with humoral immunodeficiency are at increased susceptibility to recurrent bacterial sinopulmonary tract infections, which often lead to chronic lung diseases such as bronchiectasis and COPD. ${ }^{24,25}$ Early recognition of humoral immunodeficiency and early treatment with immunoglobulin infusions reduces infections, prevents complications, and improves quality of life. ${ }^{5}$ More than $60 \%$ of AECOPD episodes are triggered by a viral and/or bacterial infections. ${ }^{12,26}$ Therefore, recurrent AECOPD may be due to recurrent infections. Since recurrent respiratory tract infections are common manifestations of humoral immunodeficiency, we suggest that impairments in the humoral immune response could lead to recurrent AECOPD in people with COPD, and that humoral immunodeficiency is more prevalent in COPD patients with a "high-risk of exacerbations phenotype" than those with a "low-risk of exacerbations phenotype" (Figure 1). Based on the Canadian Thoracic Society recommendation on stratified risk of future exacerbations, individuals with $\leq 1$ moderate AECOPD (requiring antibiotics and/or oral corticosteroids) in the last year are considered at low-risk of future exacerbations, while those with $\geq 2$ moderate or $\geq 1$ severe exacerbation (requiring hospitalization or emergency room visit) are at highrisk of future exacerbations. ${ }^{27}$

The relationship between AECOPD and humoral immune function, specifically humoral immunodeficiency, was not assessed in the reviewed studies and hence warrants further investigation. Humoral immunodeficiency can be diagnosed by dynamic testing of a specific immune response to a polysaccharide vaccine antigen, which induces an antibody response without T-cell help, the so-

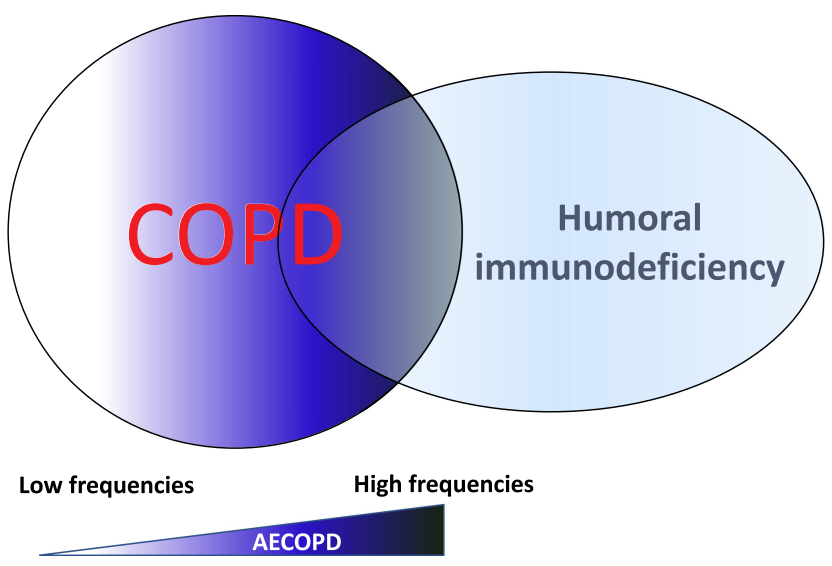

Figure I Author's proposed hypothesis. Humoral immunodeficiency is more prevalent in COPD patients with "high-risk of exacerbations phenotype" than those with a "low-risk of exacerbations phenotype". 
called T-independent antibody response. The most common polysaccharide antigen used in clinical practice is the unconjugated pneumococcal vaccine. The validity of this diagnostic test is compromised if a patient has previously responded to these vaccine antigens. Since many patients with COPD receive this vaccine as recommended, or have responded to natural infection, the pneumococcal vaccine response is not an ideal method of evaluating humoral immune function in this population. Therefore, an alternative diagnostic tool of humoral immune function is needed to investigate the effect of humoral immunity on AECOPD frequency and response to immunoglobulin treatment.

\section{Improvement of Mucosal Immunity}

Similar to the systemic immune system, the mucosal immune system is comprised of innate and adaptive components. Immunoglobulins play a major role in mucosal adaptive immunity. Among immunoglobulin classes or isotypes, $\operatorname{Ig} \mathrm{A}$ is considered a hallmark of mucosal antibody because surface epithelia are the principal sites of IgA synthesis and secretion. Nevertheless, IgG concentrations exceed those of $\operatorname{IgA}$ in the bronchoalveolar fluids, where it is the predominant antibody isotype. ${ }^{28,29} \mathrm{IgG}$ is transported through the intact epithelial layer from the basal epithelial or sub-epithelial layer by the neonatal fragmentable crystallizable $(\mathrm{Fc})$ receptor $(\mathrm{FcRn}){ }^{30}$ Parenteral administration of passive neutralizing IgG has been shown to prevent lung infection by Streptococcus pneumoniae in mice. ${ }^{31}$ It is therefore possible that parenteral administration of $\mathrm{IgG}$ increases IgG concentrations in the luminal airway, which enhances mucosal immunity. An improved mucosal immunity by this mechanism may reduce the risk of respiratory infections, and hence reduce the risk of AECOPD in COPD patients.

\section{Reestablishment of Healthy Lung Microbiome and Reduction of Airway Inflammation}

Healthy lungs contain resident commensal microbes that colonize the lining of the respiratory tract, reminiscent to what has been reported for the gastrointestinal tract. The most common bacterial genera in the lower airway among healthy individuals are Prevotella, Veillonella, and Streptococcus. ${ }^{32}$ On the other hand, pathogenic bacteria such as Haemophilus influenzae, Pseudomonas aeruginosa, Staphylococcus aureus, Streptococcus pneumoniae, and Moraxella catarrhalis ${ }^{33,34}$ are predominant in the diseased lungs of patients with COPD.
Microbial components and their metabolites have the potential to maintain immune homeostasis in the host. For example, commensal neomycin-sensitive bacteria regulate protective immune responses in the lungs against influenza A virus infections. They do so by generating virus-specific CD4 and CD8 T cells through inflammasome activation and dendritic cell migration from the site of infection to lymph nodes. Disruption of composition or the number of microbiota termed "dysbiosis" may contribute to the development, progression, or exacerbation of various inflammatory disorders of the lungs, including asthma, COPD and cystic fibrosis. ${ }^{35}$ Pathogenic bacteria can increase airway inflammation by stimulating production of inflammatory cytokines ${ }^{34,36}$ and by degrading IgA. ${ }^{37}$ We hypothesize that immunoglobulin treatment may reset 'dysbiosis' by reducing pathogenic microbes which can result in decreased airway inflammation. Given that AECOPD is characterized by heightened airway inflammation, it is indeed plausible that improved respiratory microbiome composition may reduce AECOPD frequency.

\section{Reduction of Autoantibodies in the Airways}

Over the past decade, there has been an increasing body of evidence linking autoimmunity and COPD. ${ }^{38}$ Although it has not been clearly established, serum and sputum autoantibodies (antibodies against self-antigens) may correlate with a certain COPD phenotype such as those with recurrent AECOPD. ${ }^{39}$ Immunoglobulin treatment has been used successfully to treat many immune-mediated diseases caused by autoreactive B lymphocytes. Immunoglobulin is found to exert its effect through modulation of expression and function of FcR, interference with complement activation and the cytokine network. ${ }^{40}$ Antibodies in immunoglobulin products recognize and neutralize idiotypes of disease-associated and natural autoantibodies as well as B-cell antigen receptors. Reduction in the autoantibody titer in vivo has been observed in several conditions following immunoglobulin treatment. ${ }^{41,42}$ Thus, it could be suggested that immunoglobulin may reduce AECOPD by interfering with the production or effect of autoantibodies in the airways. However, immunoglobulin dosage required for the treatment of autoimmune conditions is generally higher than the dosage used in the treatment for immunodeficient patients. We and others observed a reduction in AECOPD using the standard dosage recommended for immunodeficiency., 7 In other words, the higher immunoglobulin dosage required for the treatment of autoimmune conditions was not needed to reduce 
AECOPD frequency in COPD patients. Thus, it seems less likely that immunoglobulin treatment in patients with COPD would work by this mechanism of reducing autoantibodies in the airway.

\section{Conclusion}

In summary, the evidence of immunoglobulin efficacy in prevention of frequent recurrent AECOPD is limited. Several mechanisms have been proposed to explain how immunoglobulin might reduce recurrent AECOPD frequency and severity. It is possible that immunoglobulin works by improving IgG levels in patients with hypogammaglobulinemia or by improving humoral immune function in immunodeficient patients or by enhancing mucosal immunity in general. However, the current method of evaluating humoral immune response is not reliable in all COPD patients and hence an alternative diagnostic test is needed. It should also be noted that immunoglobulin might reduce recurrent AECOPD frequency by other mechanisms, such as via anti-inflammatory or immunomodulatory effects. Hence, identifying and treating only immunodeficient cases with COPD and recurrent AECOPD may overlook others who could benefit from immunoglobulin treatment. Rigorous and high-quality prospective trials are therefore warranted in order to identify individuals with COPD at high risk of recurrent AECOPD and to evaluate the efficacy of immunoglobulin in the prevention of AECOPD. Further, individualized evaluation of quantitative and functional antibodies in COPD patients may provide better insight into the mechanisms underlying recurrent AECOPD and also identify patients with COPD phenotypes who may benefit from immunoglobulin treatment.

\section{Data Sharing Statement}

The datasets used and/or analysed during the current study are available from the corresponding author upon reasonable request.

\section{Ethics Approval and Consent to Participate}

The ethics approval was waived due to the nature of the study. This study did not involve human or animal subjects.

\section{Acknowledgments}

We thank Ms. Risa Shorr, a librarian, for her expertise in article search and search strategy for the review.

\section{Author Contributions}

All authors made substantial contributions to conception and design, acquisition of data, or analysis and interpretation of data; took part in drafting the article or revising it critically for important intellectual content; agreed to submit to the current journal; gave final approval of the version to be published; and agree to be accountable for all aspects of the work.

\section{Funding}

There is no funding to declare for this study.

\section{Disclosure}

DWC and JC received grant funding through our institution (OHRI) from CSL Behring and Grifols for an investigatorsponsored clinical trial of IVIG in recurrent AECOPD. No influence or conflict exists, but might be perceived. JC reports grants from CSL Behring, grants from Grifols, grants from Takeda, grants and personal fees from OctaPharma, personal fees from GSK, personal fees from Sanofi, personal fees from Alexion Pharma, personal fees from EMD Serono outside the submitted work. DU and SJA do not have competing interests to declare.

\section{References}

1. Gold reports for personal use - global initiative for chronic obstructive lung disease - GOLD. Available from: https://goldcopd.org/goldreports/. Accessed August 5, 2020.

2. McGhan R, Radcliff T, Fish R, Sutherland ER, Welsh C, Make B. Predictors of rehospitalization and death after a severe exacerbation of COPD. Chest. 2007;132(6):1748-1755. doi:10.1378/chest.06-3018

3. Mittmann N, Kuramoto L, Seung SJ, Haddon JM, Bradley-Kennedy C, Fitzgerald JM. The cost of moderate and severe COPD exacerbations to the Canadian healthcare system. Respir Med. 2008;102(3):413-421.

4. Pocket guide to COPD diagnosis, management, and prevention a guide for health care professionals. 2020. Available from: www.goldcopd. org. Accessed January 13, 2021.

5. Chapel H, Prevot J, Gaspar HB, et al. Primary immune deficiencies principles of care. Front Immunol. 2014;5. doi:10.3389/ fimmu.2014.00627

6. Berger M, Murphy E, Riley P, Bergman GE; Investigators VT. Improved quality of life, immunoglobulin $G$ levels, and infection rates in patients with primary immunodeficiency diseases during self-treatment with subcutaneous immunoglobulin G. South Med J. 2010;103(9):856-863. doi:10.1097/SMJ.0b013e3181eba6ea

7. Cowan J, Gaudet L, Mulpuru S, et al. A retrospective longitudinal within-subject risk interval analysis of immunoglobulin treatment for recurrent acute exacerbation of chronic obstructive pulmonary disease. PLoS One. 2015;10(11):e0142205. doi:10.1371/journal.pone.0142205 
8. McCullagh BN, Comellas AP, Ballas ZK, Newell JD, Zimmerman MB, Azar AE. Antibody deficiency in patients with frequent exacerbations of Chronic Obstructive Pulmonary Disease (COPD). PLoS One. 2017;12(2):e0172437. doi:10.1371/journal. pone. 0172437

9. Janeway CA, Travers P, Walport M, Shlomchik MJ. Immunobiology NCBI Bookshelf. 5th ed. New York: Garland Science; 2001. Available from: https://www.ncbi.nlm.nih.gov/books/NBK10757/. Accessed January 1, 2021.

10. Mouthon L, Kazatchkine MD. Polyvalent immunoglobulins in human pathology: principles of use and indications. Med Ther. 1997;3 (10):863-868.

11. Novaretti M, Dinardo C. Immunoglobulin: production, mechanisms of action and formulations. Rev Bras Hematol Hemoter. 2011;33 (5):377-382. doi:10.5581/1516-8484.20110102

12. Papi A, Bellettato $\mathrm{CM}$, Braccioni $\mathrm{F}$, et al. Infections and airway inflammation in chronic obstructive pulmonary disease severe exacerbations. Am J Respir Crit Care Med. 2006;173 (10):1114-1121. doi:10.1164/rccm.200506-859OC

13. Robinson P, Anderson D, Brouwers M, Feasby TE, Hume H. Evidence-based guidelines on the use of intravenous immune globulin for hematologic and neurologic conditions. Transfus Med Rev. 2007;21(Suppl-1):S3-S8. doi:10.1016/j.tmrv.2007.01.004

14. Kumar A, Patwa HS, Nowak RJ. Immunoglobulin therapy in the treatment of multifocal motor neuropathy. $J$ Neurol Sci. 2017;375:190-197. doi:10.1016/j.jns.2017.01.061

15. Hartung H-P, Mouthon L, Ahmed R, Jordan S, Laupland KB, Jolles S. Clinical applications of intravenous immunoglobulins (IVIg) - beyond immunodeficiencies and neurology. Clin Exp Immunol. 2009;158:23-33. doi:10.1111/j.1365-2249.2009.04024.x

16. Edgar JDM, Richter AG, Huissoon AP, et al. Prescribing Immunoglobulin replacement therapy for patients with non-classical and secondary antibody deficiency: an analysis of the practice of clinical immunologists in the UK and Republic of Ireland. $J$ Clin Immunol. 2018;38(2):204-213. doi:10.1007/s10875-017-0469-4

17. Barth J, Jaeger D, Broder M. Is there a benefit of an additive standard immunoglobulin therapy for the clinical course of COPD patients under chronic immunosuppressive therapy? Title. Eur Respir J. 2001;18(Suppl 33):24s.

18. Leitao Filho FS, Won Ra S, Mattman A, et al. Serum IgG and risk of exacerbations and hospitalizations in chronic obstructive pulmonary disease. $J$ Allergy Clin Immunol. 2017;140(4):1164-1167.e6. doi:10.1016/j.jaci.2017.01.046

19. Holm AM, Andreassen SL, Christensen VL, et al. Hypogammaglobulinemia and risk of exacerbation and mortality in patients with COPD. Int $J$ Chron Obstruct Pulmon Dis. 2020;15:799-807. doi:10.2147/COPD.S236656

20. GOLD 2017 global strategy for the diagnosis, management and prevention of COPD - global initiative for chronic obstructive lung disease - GOLD. Available from: http://goldcopd.org/gold-2017global-strategy-diagnosis-management-prevention-copd/. Accessed July 6, 2017.

21. Settipane GA, Pudupakkam RK, McGowan JH. Corticosteroid effect on immunoglobulins. J Allergy Clin Immunol. 1978;62(3):162-166. doi:10.1016/0091-6749(78)90101-X

22. Kawano T, Matsuse H, Obase Y, et al. Hypogammaglobulinemia in steroid-dependent asthmatics correlates with the daily dose of oral prednisolone. Int Arch Allergy Immunol. 2002;128(3):240-243. doi: $10.1159 / 000064258$

23. Dhalla F, Misbah SA. Secondary antibody deficiencies. Curr Opin Allergy Clin Immunol. 2015;15(6):505-513. doi:10.1097/ ACI.0000000000000215

24. Costa-Carvalho BT, Wandalsen GF, Pulici G, Aranda CS, Sole D. Pulmonary complications in patients with antibody deficiency. Allergol Immunopathol (Madr). 2011;39(3):128-132. doi:10.1016/j. aller.2010.12.003
25. Cinetto F, Scarpa R, Rattazzi M, Agostini C. The broad spectrum of lung diseases in primary antibody deficiencies. Eur Respir Rev. 2018;27(149):180019. doi:10.1183/16000617.0019-2018

26. Kherad O, Rutschmann OT. Viral infections as a cause of chronic obstructive pulmonary disease (COPD) exacerbation. Praxis (Bern 1994). 2010;99(4):235-240. doi:10.1024/1661-8157/a000034

27. Bourbeau J, Bhutani M, Hernandez P, et al. Canadian Thoracic Society Clinical Practice Guideline on pharmacotherapy in patients with COPD - 2019 update of evidence. Can J Respir Crit Care, Sleep Med. 2019;3(4):210-232. doi:10.1080/24745332.2019.1668652

28. Kitz R, Ahrens P, Zielen S. Immunoglobulin levels in bronchoalveolar lavage fluid of children with chronic chest disease. Pediatr Pulmonol. 2000;29(6):443-451. doi:10.1002/(SICI)1099-0496(200006)29:6<443::AID-PPUL6>3.0.CO;2-M

29. Reynolds HY. Immunoglobulin $G$ and Its Function in the Human Respiratory Tract. Mayo Clin Proc. 1988;63(2):161-174. doi:10.1016/S0025-6196(12)64949-0

30. Horton RE, Vidarsson G. Antibodies and their receptors: different potential roles in mucosal defense. Front Immunol. 2013;4(JUL). doi:10.3389/fimmu.2013.00200

31. Saeland E, Vidarsson G, Leusen JHW, et al. Central role of complement in passive protection by human IgG1 and IgG2 anti-pneumococcal antibodies in mice. $J$ Immunol. 2003;170 (12):6158-6164. doi:10.4049/jimmunol.170.12.6158

32. Charlson ES, Bittinger K, Haas AR, et al. Topographical continuity of bacterial populations in the healthy human respiratory tract. $A m$ J Respir Crit Care Med. 2011;184(8):957-963. doi:10.1164/ rccm.201104-0655OC

33. Fong C, Crichton M, Cassidy A, et al. Altered lung microbiota profiles are associated with disease severity, exacerbation frequency and neutrophilic inflammation in bronchiectasis. 2016.

34. Zhang M, Li Q, Zhang X-Y, Ding X, Zhu D, Zhou X. Relevance of lower airway bacterial colonization, airway inflammation, and pulmonary function in the stable stage of chronic obstructive pulmonary disease. Eur J Clin Microbiol Infect Dis. 2010;29(12):1487-1493. doi:10.1007/s10096-010-1027-7

35. Dickson RP, Erb-Downward JR, Huffnagle GB. The role of the bacterial microbiome in lung disease. Expert Rev Respir Med. 2013;7(3):245-257. doi:10.1586/ers.13.24

36. Tufvesson E, Bjermer L, Ekberg M. Patients with chronic obstructive pulmonary disease and chronically colonized with Haemophilus influenzae during stable disease phase have increased airway inflammation. Int J Chron Obstruct Pulmon Dis. 2015;10:881-889. doi:10.2147/COPD.S78748

37. Murphy TF, Kirkham C, Jones MM, Sethi S, Kong Y, Pettigrew MM. Expression of IgA proteases by haemophilus influenzae in the respiratory tract of adults with chronic obstructive pulmonary disease. J Infect Dis. 2015;212(11):1798-1805. doi:10.1093/infdis/ jiv299

38. Wen L, Krauss-Etschmann S, Petersen F, Yu X. Autoantibodies in chronic obstructive pulmonary disease. Front Immunol. 2018;9 (JAN):66. doi:10.3389/fimmu.2018.00066

39. Liang Z, Wang F, Zhang D, et al. Sputum and serum autoantibody profiles and their clinical correlation patterns in COPD patients with and without eosinophilic airway inflammation. J Thorac Dis. 2020;12 (6):3085-3100. doi:10.21037/jtd-20-545

40. Negi VS, Elluru S, Sibéril S, et al. Intravenous immunoglobulin: an update on the clinical use and mechanisms of action. J Clin Immunol. 2007;27(3):233-245. doi:10.1007/s10875-007-9088-9

41. Liblau R, Gajdos P, Bustarret FA, El Habib R, Bach JF, Morel E. Intravenous $\gamma$-globulin in myasthenia gravis: interaction with antiacetylcholine receptor autoantibodies. J Clin Immunol. 1991;11 (3):128-131. doi:10.1007/BF00918680

42. Sami N, Bhol KC, Ahmed AR. Influence of IVIg therapy on autoantibody titers to desmoglein 1 in patients with pemphigus foliaceus. Clin Immunol. 2002;105(2):192-198. doi:10.1006/clim.2002.5278 


\section{Publish your work in this journal}

The International Journal of COPD is an international, peer-reviewed journal of therapeutics and pharmacology focusing on concise rapid reporting of clinical studies and reviews in COPD. Special focus is given to the pathophysiological processes underlying the disease, intervention programs, patient focused education, and self management protocols. This journal is indexed on PubMed Central, MedLine and CAS. The manuscript management system is completely online and includes a very quick and fair peer-review system, which is all easy to use. Visit http://www.dovepress.com/testimonials.php to read real quotes from published authors. 